\title{
Analysis of Closed Loop Chopper Controlled Drive for PMDC Motors using PID Controller
}

\author{
G. Murugananth ${ }^{1}$, S. Vijayan ${ }^{2}$, S. Muthukrishnan ${ }^{3}$ \\ ${ }^{I}$ Dept. of Electrical and Electronics Engineering, Pollachi Institute of Engineering and Technology, Pollachi, \\ Tamilnadu, India \\ ${ }^{2}$ Principal, Surya Engineering College, Mettukkadai, Erode, Tamilnadu, India \\ ${ }^{3}$ Dept. of Electronics and Communication Engineering, Sri Eshwar College of Engineering, Coimbatore, \\ Tamilnadu, India
}

\begin{abstract}
In orthopedic surgical simulators PMDC motors are used. A closed loop chopper controlled scheme employing PID controller is attempted in this paper, which employs two power electronic switches one for ON/OFF control and the other for speed control. The ON/OFF Control loop uses a hysteresis controller and a PID controller is used for effective speed control of the motor. The closed loop system is simulated using Matlab/Simulink. The responses of both the loops were analysed. The simulation results infer that this scheme can give efficient control of the motor.
\end{abstract}

Keywords: Chopper, Hysteresis controller, Orthopedic Surgical Simulators, PMDC motor, PID Controller

\section{INTRODUCTION}

Novice surgeons practice screw placements in bones using orthopedic surgical simulators. The simulators are used for bone drilling and screw placements [1] \& [2]. The simulations are carried out in cadaver bones and not on live patients. The screw placement is achieved in three phases namely insertion, tightening and stripping. Depending on the screw geometry and bone strength, the torque and speed required for drilling and screwing are fixed. The torque applied should be such that optimal tightening is achieved [3], [4], [5], [6] \& [7]. The permanent magnet DC motors are used in the simulators due to their high torque output. The mathematical model for analysing the system is derived [8] \& [9]. In PMDC motors, the speed can be varied by varying the armature voltage [10]. Half controlled converters and fully controlled converters are widely used for drilling operations [11] \& [12]. In this paper a closed loop chopper controlled drive system for the PMDC motor with inner ON/OFF control and outer speed control loops is presented. The inner ON/OFF control loop utilizes a hysteresis controller and the outer speed control loop employs a PID controller to regulate the speed.

\section{MATHEMATICAL MODEL OF PMDC MOTOR}

A PMDC motor becomes the best choice in surgical operations because of their linear speed torque characteristics. They required less electric power input and also have quiet operation. The simplified model of the motor is shown in Fig. 1.

$$
\begin{aligned}
& V=E+I a R a+L a \frac{d I a}{d t} \\
& E=K_{1} \omega \\
& T_{E}=T_{L}+B \omega+J \frac{d \omega}{d t} \\
& T_{E}=K_{2} I a
\end{aligned}
$$

Where,

$\mathrm{R}_{\mathrm{a}}$ is armature resistance in Ohms

$\mathrm{L}_{\mathrm{a}}$ is armature inductance in $\mathrm{H}$

$\mathrm{I}_{\mathrm{a}}$ is armature current in A

$\mathrm{E}$ is back EMF in Volts

$\mathrm{K}_{1}$ is voltage constant in volts sec/rads

$\omega$ is angular speed in rads/sec

$\mathrm{T}_{\mathrm{E}}$ is electromagnetic torque developed in $\mathrm{Nm}$

$\mathrm{T}_{\mathrm{L}}$ is load torque in $\mathrm{Nm}$

$\mathrm{J}$ is Moment of Inertia in $\mathrm{kg} \cdot \mathrm{m}^{2} / \mathrm{s}^{2}$ 


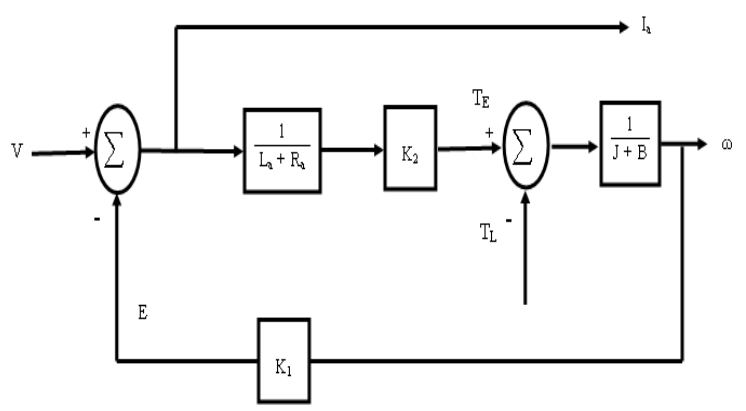

Fig.1. Mathematical Model of PMDC Motor

\subsection{ON/OFF Control}

\section{PROPOSED CHOPPER CONTROLLED SYSTEM}

The block diagram of the proposed system is shown in Fig. 2. S1 and S2 are two power electronic switches. Switch S2 is used for ON/OFF control and S1 is for speed control of the motor. In PMDC motors, torque is proportional to current. The resistive force offered by the fractured bone towards drilling force will be less compared to un-fractured bone. During drilling when the drill bit touches the un-fractured bones, the torque requirement increases as its strength is more. This in turn increases the current drawn by the motor, so the current value exceeds the set value. The comparator generates the error values based on these current values and the hysteresis controller drives the switch S2 such that drilling is stopped.

\subsection{Speed Control}

During surgical operations bone drilling and screw tightens needs different speed levels. Based on the operation the set speed is fixed. Then the speed of the machine is sensed and compared with the set value. The error generated is processed by the PID controller and it generates the PWM signal required pulses to drive switch S1. Thus the voltage fed to the armature of the motor is varied and the speed is controlled.

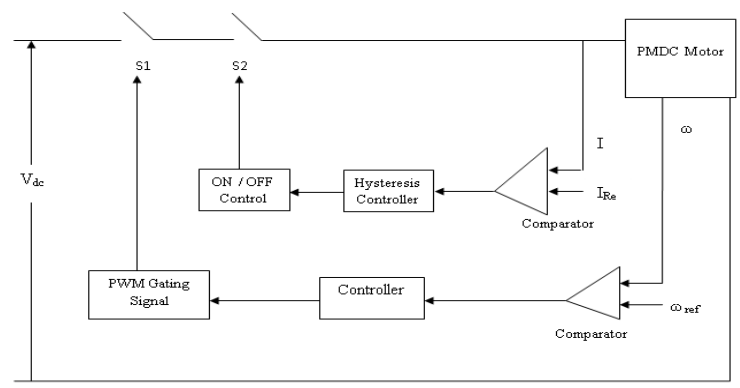

Fig. 2. Block Diagram of the System

\section{Simulation Results}

The proposed system is simulated using Matlab Simulink. The ON/OFF control loop is tested by varying the torque values. The torque value is varied over a period of simulation and the response of the ON/OFF loop is studied. It's found that the system responds immediately for the change in torque value and makes the switch $\mathrm{s} 2$ to be switched off. The response of the system is shown in figure 3 . The response implicit that after the settling period when the torque exceeds the set torque value, the switch S2 is switched off by the hysteresis controller. This reduces the speed of the motor to be zero.

The transient state properties of the PID controller are measured from the simulation results. To examine the robustness of the outer chopper control loop, various speed values are set and the corresponding values are tabulated in table 1. The tabulated results infer that the use of PID controllers reduces the maximum peak overshoot and also the steady state error. 


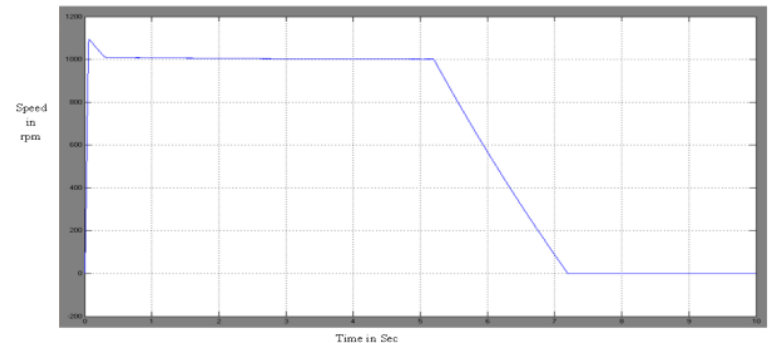

Fig.3. Response of the PID Controller

Table 1

Performance of PI Controller

\begin{tabular}{|l|c|c|c|}
\hline \multicolumn{1}{|c|}{ Parameter } & Speed = 600 rpm & Speed = 900 rpm & Speed = 1200 rpm \\
\hline Maximum Peak Overshoot (\%) & 9.9 & 8.6 & 7.2 \\
\hline Steady State Error (\%) & 0.9 & 1.2 & 1.4 \\
\hline Rise time (s) & 0.067 & 0.065 & 0.065 \\
\hline Settling time (s) & 0.35 & 0.33 & 0.33 \\
\hline
\end{tabular}

\section{Conclusion}

A closed loop chopper controlled system with two power electronic switches is presented. The system is simulated and the performance of the ON/OFF and the speed control systems were tested. The torque values are varied for ON/OFF control switch and the results shows that the motor is stopped when there is sudden increase in torque. The speed control system utilized a PID controller and its transient sate response is tabulated for various speed values. The results conclude that the response of the proposed system makes this system to be suitable and can be employed for drilling and screwing in orthopedic surgical simulators.

\section{REFERENCES}

[1] Ann Majewicz, Jason Glasser, Rosemary Bauer, Stephen M. Belkoff, Simon C. Mears, Allison M. Okamur, "Design of a Haptic Simulator for Osteosynthesis Screw Insertion”, IEEE Haptics Symposium 2010, Waltham, Massachusetts, USA, pp. 497-500, 25 26 March 2010.

[2] Chantelle Saegenschnitter, Tania Walker, "Orthopedic surgical simulator", S.M.B.E. (SA) Inc. Newsletter Vol. X1 No 1, pp1-2,2003.

[3] R. Thomas, et al., "Automated surgical screwdriver: Automated screw placement", Proceedings of the Institution of Mechanical Engineers, vol. 222, No. 5, pp. 451-454, June 2008.

[4] Ming-Dar Tsai, Ming-Shium Hsieh, Chiung-Hsin Tsai, "Bone drilling haptic interaction for orthopedic surgical simulator", ELSEVIER - Computers in Biology and Medicine, volume 3, No. 1, pp. 1709-1718, 2007.

[5] Olga Sourina, Alexei Sourin, Howe Tet Sen,"Orthopedic Surgery Training Simulation", Journal of Mechanics in Medicine and Biology, Volume 7, No. 1 pp. 37-53, 2007.

[6] Robert V. O' Toole, Branklajva Ramaz, Anthony M, DrrGlora III, Chrsitopher. D, Visnica and Robert H. Reid, "Biomechanics for Preoperative Planning and Surgical Simulations in Orthopedics", ELSEVIER - Computers in Biology and Medicine, volume 25, No. 2 , pp183-191, 1995 .

[7] R. Sankar, S. Ramareddy, “A Novel Control Strategy Using Neuro-Fuzzy Controller for PMDC Drive”, European Journal of Scientific Research, Volume 54 No.1, pp.29-45, 2011.

[8] N. Chandrasekaran, K. Thiyagarajah, "Modeling and MATLAB Simulation of Pumping System using PMDC Motor Powered by Solar System", European Journal of Scientific Research, Volume 59 No.1, pp.6-13, 2011.

[9] Michael E. Fisher Arindam Ghosh Adel M. Sharaf, "Intelligent Control Strategies for Permanent Magnet DC Motor Drives", Proceedings of the 1996 International Conference on Power Electronics, Drives and Energy Systems for Industrial Growth, Volume No. 1,pp. 360-366, 8-11 January 1996.

[10] Nitai Pal, Pradip Kumar Sadhu and R. Swaroop, "Closed Loop Speed Control of DC Motors used in Rock Drilling and Mud Pump Application", Proceedings of the International Multi conference of Engineers and Computer Scientists, Volume 2, pp. 14-16, March 2012.

[11] M.Ramamoorty and B.Ilango, "The Transient Response of a Thyristor-Controlled Series Motor", IEEE Trans. on PAS, Vol PAS90, No.1, pp. 289-297, 1971.

[12] A.Yablon, and J.Applebaum, "Transient Analysis of DC Series Motor (Linear Versus Nonlinear Models)", IEEE Trans. on Ind. Electron. And Contr. Instrum., Vol. IECI-28, No. 2, pp. 120-125, 1981. 